\title{
Ambiguity and Choice in European Public Policy
}

\author{
Draft! Comments welcome!
}

\author{
Nikolaos Zahariadis \\ Department of Government \\ University of Alabama at Birmingham \\ Birmingham AL 35294 \\ nzaharia@uab.edu
}

Paper prepared for presentation at the biannual meeting of the European Union Studies Association, Montreal, Canada, May 17-19, 2007.

\begin{abstract}
I apply the multiple streams lens, which was originally developed to explain agenda-setting in national systems, to the EU policy formation (agenda-setting and decision-making) process. Choice is the result of coupling by policy entrepreneurs of three relatively independent streams - problems, politics, and policies. Each stream is conceptualized as having a life and dynamics of its own. At fortuitous moments in time, skilled policy entrepreneurs will attempt to couple the streams together by "selling" their pet package of problem and policy to a receptive political audience. The chances that a particular policy will be adopted increase when all three streams are coupled together. I conclude with implications for the debate of the role of institutions, actors, and ideas in EU policy-making and a clarification of two paradoxes of EU policy. The first paradox stresses the centrality of political power in the absence of institutional hierarchies. The second paradox highlights but also circumscribes the role of epistemic communities in the EU.
\end{abstract}


The process of making policy at the European Union (EU) level is often characterized as fluid, complex, and incomprehensible. It contains all the properties of what Weick (2001) has called a loosely coupled system, whose main characteristic is a high degree of ambiguity. Participants often don't have clearly formulated goals; they drift in and out of decisions, while the whole process is so complex that it is poorly understood by most. For this reason, scholars have repeatedly suggested that multiple streams is a good way to analyze EU policies. The lens, inspired by Cohen et al's (1972) garbage can model and Kingdon's (1995) reformulation of it, assumes ambiguity is an integral part of the policy making process. Peters (1994), Olsen (2001), and Andersen and Eliassen $(2001,11)$ conceptualize the complexity and heterogeneity in the EU as producing what Richardson (2001) has termed as "an emerging garbage can.” The loosely coupled processes they observe produce ambiguity and lead to significant variability in outcomes. Richardson $(2001,22,13)$ claims that "EU policy...often seems like Kingdon’s ‘primeval soup' [because it] fits well with what we already know about some aspects of the EU.” However, despite praising the lens' potential, few attempts have been made to-date to adapt such a model of domestic policy choice to the EU level.

In this paper I apply multiple streams to EU policy, using examples to illustrate my points and to derive hypotheses; no attempt is made to test the hypotheses. Multiple streams has been hailed as one of "the more promising" and widely used theoretical frameworks of the national policy process (Sabatier 2007, 7), but despite its asserted potential, it has not been applied to the EU (but see Corbett 2005). I do so, taking the lens beyond agenda-setting to the entire EU process of policy formation (agenda-setting and decision-making). I narrow the locus of inquiry exclusively to the EU level without examining the impact such decisions may have on member state policies. The argument differs from prevailing conceptions of multilevel governance. Such theorizing argues that the European level is a collection of international, national, and sub-national levels all of which must be viewed as constituting a whole (Hooghe and Marks 2001).Under these conditions, the study of public policy cannot clearly distinguish between national, subnational, and European policies (Zahariadis 2002). I draw the distinction to focus on what may be termed as the horizontal dimension of the EU, i.e., the collective institutional level, instead of its vertical dimension, i.e., the EU-member state level. ${ }^{1}$

I briefly review approaches to EU policy-making. Then I introduce multiple streams by highlighting what is meant by a loosely coupled system; I argue the EU fits the description well. The section is followed by a detailed examination of the various elements and processes of the multiple streams lens and their implications for EU policy. I conclude with implications for the debate of the role of institutions, actors, and ideas in EU policy-making and a clarification of two features of EU policy. The first stresses the centrality of political power in the absence of institutional hierarchies. The second highlights but also circumscribes the role of epistemic communities in the EU.

\section{Perspectives on European Policy-Making}

Conventional wisdom claims that no one theory can explain the entire EU policy process; rather multiple theories may be appropriate at different levels or stages of 
analysis. This is good advice when policy analysis is at its infancy, but the study of EU policy has reached a point of maturation when a second step is feasible: to begin developing better theories of the EU policy process that transcend levels or stages of analysis and still explain a good portion of the variance in policy outcomes. Such work has already been done at the national level (Sabatier 2007), but not at the EU level. Perhaps the reason is because the EU has for a long time been viewed as sui generis. As a result, analysts have sought to develop unique concepts and theories to fit the peculiarities of the EU arena. However, although some institutional features are unique, there is no reason to suppose that the activities of the participants in the EU policy process "have different purposes simply because the institutional arena is different from the other in which they may be involved. The politics of the EU are just that-normal politics, with whatever one thinks are the normal features of domestic politics, and by extension policy-making -in European countries” (Wallace et al 2005, 10). I begin with this premise and adapt a lens of domestic policy-making to the EU level.

Current theorizing is incomplete as analysts narrow down the study of the EU policy process to different levels (Peterson 1995), stages (Richardson 2001), or issues (Majone 1996). Peterson (1995) presents a decision-making framework where decisions are divided into three levels or types. The first is the supersystemic level which involves largely constitutional issues and looks at history-making decisions, such as the Single European Act. The second level involves policy-setting decisions at the systemic level. Finally, there are policy-shaping decisions which are made at the sub-systemic level. Intergovernmentalism or neo-functionalism is "best" at the first level, new institutionalism in the second, and policy network analysis in the third.

Richardson (2001) advocates the familiar stage heuristic as a good way of dividing labor and utilizing concepts already well developed in national accounts of policy-making. Combining stages with theoretical tools, Richardson proposes an eclectic approach to theory development where different tools are considered useful at different stages of the policy process. For example, he maintains that epistemic communities (Haas 1992) are a good tool to provide insight at the agenda stage whereas Sabatier and Weible's (2007) analysis of advocacy coalitions may prove more useful at the decision making stage.

Majone (1996) stresses the characteristics of issues as the driving force in explaining the types of politics and policy-making that will emerge. He views integration as better suiting European level institutions when it involves regulatory issues. This is because it is a low-cost method of policy-making in the context of a resource-constrained EU. There are also powerful incentives for the Commission to supply regulation stemming from the founding treaties and the demand by business due to the perceived cost efficiencies of dealing with only one institution, contingent upon the discretion conferred by national governments (Pollack 2003). This stands in stark contrast to social policy, which involves largely redistributive politics and zero-sum gains.

The problem with these perspectives is they are eclectic with little or any guidance as to why one model may be more appropriate or better than the others. Each 
model rests on unique assumptions, making it difficult to extend knowledge beyond the narrow confines of applicability to either stages or levels. Moreover, the split of the process to stages or levels leaves both approaches vulnerable to the same criticisms leveled at similar debates at the domestic level. There can be a potentially endless paring down of the process, leading to fragmentation and gaps in knowledge cumulation (Sabatier 1991). The issue perspective is less eclectic, but it assumes rationality and coherence even in areas where it may not be present. For example, even if one were to assume that the Commission acts as a monolith, issues are not always thrust upon the agenda as a result of discretionary power. The policy-making process is not linear where solutions always aim to solve problems on the basis of cost-benefit analysis. We need models that don't negate the value of these arguments but have the capacity to go beyond them.

\section{The EU as a loosely coupled system}

The EU may be accurately described as a loosely coupled system. As Weick (2001, 384) puts it, "to talk about a loosely coupled system is not to talk about structural looseness, but about process looseness." Such systems focus on the links and autonomy among constituent parts. A loosely coupled system maintains high internal differentiation among units, low system integration, and a high capacity via mechanisms of autonomy and coherence "to combine the contradictory elements of connection and autonomy" (Orton and Weick 1990, 216). A central element of a loosely coupled system is a high degree of ambiguity. Loose couplings produce indeterminacy in that systemic events unfold unpredictably, unevenly, sporadically, and discontinuously (Weick 2001, 384). Such indeterminacy highlights disconnections between information and decision activities leading to ambiguity in terms of problematic preferences, unclear technology, and fluid participation (Cohen et al 1972). The EU approximates this description well (Peters 1994; Richardson 2001). It can be conceptualized as a fragmented polity but not a state (Hix 2005). Yet it does perform essential functions. Funds, for example, are distributed to various regions in the Union despite the number and high institutional differentiation among the directorates general (DG's) of the Commission and the often problematic preferences of the actors involved in the process (Heinelt et al 2003).

Ambiguity means three things in the policy process. First, participants often have unclear goals. As Zahariadis (2003a, 3) puts it, "quite often time constraints force politicians to make decisions without having formulated precise preferences. Decisions are made and may be facilitated by opaqueness.” For example, Sharkansky (2002, 69-70) maintains that vagueness of objectives is a good way of coping with complex and conflicting political demands. Citizens have a limited understanding of the EU and quite often they don't know what to expect or what to demand of it. Similarly, many policy makers and other officials involved in EU decisions have limited or no goals. For example, during the Yugoslav crisis in the early 1990s, few national government officials, with the possible exceptions of the Germans and Greeks, actually had a strong opinion about what to do. 
Second, participation in EU decisions is fluid. Turnover among national government officials is high and participants drift from one decision arena to the nextwith the possible exception of COREPER members. Bureaucrats at the Commission are instrumental in drafting legislation, but their ability to participate and influence the outcome at later stages of the decision decreases dramatically. The European Parliament has limited powers as a conditional agenda-setter (Tsebelis 1994), and the ability of its members to adopt EU legislation differs dramatically across time and issues. Moreover, transnational groups and NGO's exercise a strong influence on whether, when, and what form some decisions will take. As a result, the same participants don't necessarily track the same issue throughout the decision stages.

Third, organizational technology is opaque. While specific participants make be aware of their individual responsibilities and place within the EU policy process, they often exhibit rudimentary knowledge of the whole process. Jurisdictional boundaries are blurred, particularly in areas such as trade or foreign policy where the Council, the Commission, and the Parliament share responsibilities. The end result is turf battles and interagency conflict, making the process highly unstable. Add to this a plethora of different decision rules_ — such as co-decision, consultation, and the like-and the process becomes highly incomprehensible to most. As Kingdon (1995) aptly puts it in reference to the US government, the left hand does not know what the right is doing.

Under such conditions, rational models of policy making are of limited utility. There can be no goal-intending or interest-pursuing behavior if goals have not been clearly formulated prior to the decision. Distinguishing between relevant and irrelevant information is problematic. Policies cannot address problems because problem definitions are vague and constantly shifting (Zahariadis 2007, 67). Multiple streams, which is a lens of policy-making stressing temporal order and political manipulation, is a better choice.

Who pays attention to what and when is critical in understanding what decisions are made and why. Ekengren $(2002,85)$ perceptively informs that "European governance erodes the idea of a singular national timetable.” A source of ambiguity, therefore, stems from the temporal structure of European governance. Because national governments (or other actors) cannot singularly control the European agenda, the numbers of forums and working groups coupled with the simultaneous meetings that need to be attended to address European issues have rendered national government preferences to a state of constant formation.

Political manipulation provides the logic of analysis (Zahariadis 2003a). Under tight deadlines and problematic preferences, knowledge of issues and process provide the keys to unlock the puzzle of choice. Manipulation refers to the bending of ideas and institutions by policy entrepreneurs-individuals with access, resources, time, and energy - who try to get their pet proposals adopted. Knowledge of the process is important because entrepreneurs must behave strategically to activate attention to their pet issues and proposals. Substantive knowledge of the issues is also important because entrepreneurs must also "sell” their package of problem and solution to a receptive 
political audience. Information is strategically manipulated to serve different aims for different elements of the policy process.

Not all policies may be accurately explained by the multiple streams lens. Some EU decisions are made in a more rational, goal-intending fashion. For example, getting the British refund was the result of rational strategies and the determination by the British government to use EU rules to achieve its objectives. Multiple streams is most suitable in those EU “decision situations” where ambiguity appears to accurately describe the situation (Richardson 2001, 13).

\section{Elements of multiple streams}

Multiple streams argues that EU policies are the result of coupling by policy entrepreneurs of three relatively independent streams_-problems, politics, and policiesduring politically opportune moments. Each stream is conceptualized as having a life and dynamics of its own. At fortuitous moments in time, labeled policy windows, skilled individuals or corporate actors, called policy entrepreneurs, attempt to couple the streams together by "selling” their pet package of problem and policy to a receptive political audience. The chances that a particular policy will be adopted increase when all three streams are coupled together. The argument is represented schematically in Figure 1.

Figure 1 about here

\section{The problem stream}

The problem stream consists of various conditions that policy makers and citizens want addressed. Examples are government budget deficits, environmental disasters, inflation, rising medical costs, and so on. Policy makers find out about these conditions by way of indicators, focusing events, and feedback. Indicators may be used to assess the existence, magnitude of a condition, and the scope of change - for example, the cost of a program, infant mortality rates, or highway deaths. Indicators can be monitored either routinely or through special studies. For example, special studies occasionally seek to estimate the impact of subsidies on European agricultural production and prices. The indicators then can be used "politically" to measure the magnitude of change in the hope of catching official attention (Stone 2002). Calls to reform the Common Agricultural Policy have been routinely bolstered by such findings. Of course, not all conditions become problems. As Kingdon (1995, 110) categorically asserts, problems contain a "perceptual, interpretive element." Some conditions come to be defined as problems and consequently receive more attention than others (Rochefort and Cobb 1994). How is this done? A range of values is normally associated with a particular issue. Changes in specific conditions may violate those values and therefore activate interest and attention. People define conditions as problems by letting their values and beliefs guide their decisions, by placing subjects under one category rather than another, by comparing current to past performance, and by comparing conditions in different countries. 
The latter mechanism is particularly interesting in the EU case because it may involve comparing conditions among countries within the Union or between it and other countries. For example, comparing the price of automobiles across member states can be used to justify (or oppose) harmonization of tax rates across member states. The problem is that consumer in different countries pay different taxes, creating considerable variance in final price. EU total factor productivity, as a whole, has also been compared to that of the United States, Japan, and other countries in order to deficiencies (if any) and call attention to potential tax breaks or other remedies. In the latter case, national variations within the EU are less important as are cross-national ones between the EU and others.

Focusing events also draw attention to problematic conditions (Birkland 2004). Conditions and focusing events direct attention to specific evaluative dimensions of particular problems; attention is fixed by the media or policy entrepreneurs (Jones, 1994). There are two types of focusing events that may become EU problems: international and national. On an international level focusing events, such as the events of 9/11 in the US, have led to significant changes in security policy throughout the EU regarding terrorism and related activities. Closer to home, military operations in Kosovo in early 1999 brought to limelight the unmistakable lack of EU power to enforce its decisions. In similar fashion, the dispute between Russia and Ukraine in 2006 made abundantly clear the EU's energy vulnerability due to its heavy reliance on a single source, Russia. On a national level, focusing events may draw an EU response. For example, the attempt to pass through British security explosives in liquid form has led to an EU-wide policy of banning such substances from being taken on airplanes, with specific exceptions. Whether man-made and to an extent predictable, such as budget deficits or wars, or natural and unpredictable, such as the bird flu or the BSE crises, problems focus attention on issues and propel them high on the agenda.

Feedback from previous programs is important in that it helps highlight what works and what doesn't. Of special note is the European Court of Justice's rulings, which have occasionally provided the impetus for integration in new areas. For example, some rulings, as in the Dassonville and Cassis de Dijon cases, had significant implications for a variety of areas, whereas others, such as the Philip Morris case, proved catalytic in the specific area of Europe-wide mergers (Wincott 2001). Programmatic feedback also provides information back into the system that catalyzes changes not only in the direction of policy but also in the structure of the EU policy-making system itself (Richardson 2000). The story of European integration is that of path dependence (Pierson 1996). Past decisions and institutions affect present decisions and limit future courses of action. How is that done? In this case, one needs to differentiate between negative and positive feedback. Negative feedback raises the possibility of corrective action. For example, the problem of creating the single European market made it very clear that cross-national mergers and acquisitions could not be monitored simply by national competition authorities (Cini and McGowan 1998). Positive feedback, on the other hand, prompts a favorable rather than a corrective response. The positive results of the program open the possibility of policy moving further in the same direction (Pierson 2000). Put differently, positive feedback occurs when a change causes further changes to be amplified (Jones and Baumgartner 2005). For example, the “creeping competence” of the Commission is 
due not only to the willingness of member states to delegate discretionary authority to the Commission but also to the success of its previous regulatory functions (Pollack 2003; Majone 1996). Regulation begets regulation; as the Commission acquires more competence and skill in one area, it also acquires legitimacy. It can, therefore, claim competence in "neighboring” areas, not currently under its jurisdiction, simply on the basis of previous success and legitimacy. The whole conflict over subsidiarity may be explained less by a rational rule of efficiency and effectiveness and more by positive or negative feedback transmitted throughout the system via loose couplings (Zahariadis 2003b).

Successfully implementing a solution in one area may spill over to another facilitating the adoption of the same solution in a seemingly unrelated area. The concept is akin to the neo-functionalist concept of integration spillover. Success in one area makes it easier to place-or legitimizes the placement of — the same issue on the agenda in another area. The liberalization of telecommunications and the resultant benefits have paved the way to argue for similar changes in energy policy.

Attention is to an extent a function of what else preoccupies the minds of policy makers. Problems, caused either by more demands or reduced problem-solving capacity, tend to appear intractable when more of them crowd the agenda. Problem load, that is, the number of difficult problems occupying the attention of policy makers, has a significant negative effect on the efficient utilization of information and a nonlinear negative effect on problem activation (Zahariadis 2003a, chapter 6). More difficult problems require significant and expensive information gathering and processing efforts. Quite naturally when policy makers are faced with many difficult problems, they are likely to spend more time and resources processing information that may be irrelevant. Efficiency of information utilization decreases while the time spent on producing and disseminating information grows longer. Problem load has a non-linear impact on problem activationthe number of problems remaining active but not addressed on the agenda. Light loads are associated with more activation. When there are mostly easy problems to solve, problem activation and by consequence decision conflict are up. This is because easy problems crowd the agenda leading to a loss of urgency and the need to prioritize. Competition for attention stiffens without any increase in the capacity to address the problems. As a result, political conflict increases dramatically. Medium loads lessen activation, but heavier loads increase it dramatically. More difficult problems lead to more discussion but less action. Increased levels of frustration are the likely outcome. As the number of problems addressed by the EU continues to climb, the end result is more political conflict and less efficiency.

Under these conditions, attention shifts quite rapidly, abruptly, and unpredictably from one problem to the other or one dimension of the problem to another. Couplings between the various parts of the process are further loosened, enhancing ambiguity (Weick 2001, 44-8). Conditions are ripe for political manipulation by those with expertise and intimate knowledge of the process of policy-making.

The politics stream 
Three factors are important in the national politics stream: administrative or legislative turnover, pressure-group campaigns, and the national mood (Kingdon 1995). Of the three factors, the combination of the national mood and turnover in government exerts the most powerful effect on choice. However, a cross-national examination has concluded that the first two factors may be combined in light of the dominance of political parties in European national politics (Zahariadis 1995). After all, decisions are made by partisan policy makers.

EU politics differs from either analytical picture because the legislative body of the Parliament is not the supreme lawmaker and institutional rules of decision-making are fluid and shifting. Besides, public mobilization plays a lesser role in EU decisions (Princen 2007). In light of these differences, three factors are hypothesized as being relevant in the politics stream: the balance of Council member national and partisan affiliation, the ideological balance of parties in Parliament, and the European mood. Of the three factors, the Council has the most influence; but the combination of Council member ideology and the European mood exerts the greatest impact on policy choice. Because members of Parliament are elected along national lines and the institution is involved in an advisory capacity in many instances — unlike the Council-its effects are likely to be less than those of the Council.

It's no secret; parties matter in domestic policy-making. Scores of studies have found empirical evidence, supporting the argument that different parties pursue different policies to satisfy the ideology or perceived needs of their voters (e.g., Garrett 1998). When elected ministers attend the Council, they don't drop their partisan "hat," they simply add to it. They also represent their national interest, however vaguely that may be formulated. Politics in the Council is therefore a bit more complicated than in domestic policy-making. Using the ideological complexion of Ministers in some aggregative fashion will not suffice as a guide to successfully predicting what policies may be adopted. National interests also make a difference. The influx of new faces in the Council may alter the dynamics of agreement in the politics stream. It may propel some issues to the top of the agenda and drown out others. It may also facilitate agreement in some options but not others. For example, an influx of mostly Social Democrats in European capitals will alter the dynamics of support for expanded labor protections at the EU level. At the same time, the absence of strong Conservatives from the table, e.g., the United Kingdom in 1997, lessened opposition to the Social Charter. But ideology is not enough; national proclivities also make a difference. For example, the pro-integration instincts of the German Christian Democrats contrast sharply with the anti-integration stance of the British Conservatives. Though not as prominent as it used to be, the Left-Right divide continues to provide a useful tool for exploring the dynamics of the politics stream, coupled with a careful examination of national representation.

Similar dynamics may be observed in the European Parliament although the national element is less prominent. Because members are elected, organized, and seated on the basis of partisan affiliation, ideological complexion is a very important guide to accurately predicting what kind of policies will animate members and what language 
should be used to do so. For example, the influx of a majority of Social Democrats in the Parliament will almost certainly bring attention to labor and welfare issues and create an institutional majority that is more likely to support policies that enhance worker rights or establish minimal welfare protection across the EU. Though less prominent, the national dimension is not absent. In issues of supreme national importance, e.g., the possibility of Turkish membership, members of different parties still coalesce largely along national lines, e.g. Greeks or Cypriots, to protect "the national interest."

Although the concept is hard to pin down, the mood refers to the "climate of the times," the idea that important policy makers, opinion leaders, and other politicos think along similar lines (Kingdon 1995, 148). In domestic politics, the government senses the national mood, which swings from time to time, and seeks to capitalize from it by adopting policies that coincide with it. In this sense, mood plays an important role in not only constraining public policy by showing what the limits of the possible are, but it also shapes policy by pointing toward some policies and away from others.

European public opinion has traditionally played a lesser role in EU policymaking, implying that the mood is less important. The reasons for the weakness of the European relative to the national mood reside in the national politics of each member state and the absence of a European education system. European elections are still contested along national lines and issues (Franklin 2001). Although the concept of the national interest is amorphous and changing, it still exists in the imagination of national politicians and publics. A distinct equivalent concept has yet to be formulated at the EU level. Moreover, national policy makers frequently utilize higher order symbols to reach out and mobilize the entire nation in support of certain solutions (Elder and Cobb 1983). ${ }^{2}$ The absence of a European education system that will imbue a common identity replete with symbols and ideology of commonality to disparate national citizens tempers the effect of the European mood.

Nevertheless, there exists a European climate of the times that has an impact. The story of European integration is replete with periods of "eurosclerosis" and "europhoria." For example, the late 1970s and early 1980s may be characterized as a period of "eurosclerosis" that included pessimism among elites, interest groups, and the public at large about European integration. In contrast, the late 1980s and early 1990s were generally a period of great optimism and enthusiasm about the prospect of greater integration. Ideas such as the single European market or the Maastricht Treaty would probably have encountered strong opposition if they were brought up in the 1970s. The mood provides a guide to policy makers as to the general limits of public acceptance. Ideas coinciding with the mood gain greater legitimacy and "currency." Those going against the flow, such as a Europe-wide pension system, face an uphill battle to gain acceptance.

The policy stream

Whether a solution, idea, or policy—I use the terms interchangeably—is ripe for adoption depends on its availability in the policy stream. That's a function of two 
elements: the dynamics of competition among ideas and the structure of policy networks where the ideas germinate.

The policy stream consists of a "primeval soup” of ideas advocated by specialists in policy networks. The specialists are individuals who share a common concern in narrowly defined policy sectors, such as telecommunications or competition, and define problems and propose solutions to those problems. They may include Commission officials, parliamentary staffers, national Ministry experts, academics, industrialists, unionists, consumer advocates, and others. Ideas compete for consideration and adoption in such fora as Commission papers, consultation rounds, parliamentary hearings, academic journals, and others. While the number of ideas floating in the soup is very large, few ever receive serious consideration by many participants in the network. Due to processing limitations, the number of ideas must be narrowed down significantly.

Some ideas survive the period of consideration largely in tact, while others are combined into new proposals or just disappear. Whether an idea bubbles to the top of the stream, i.e., becomes ripe for consideration and adoption, depends on two factors: value acceptability and technical feasibility. Value acceptability refers to the degree of agreement among major participants in the policy stream and does not span the entire spectrum of all EU policy makers. An idea that has the support of many participants in the narrow policy stream stands a greater chance of being adopted than one that doesn't. Of course there is no "majority" rule; but it stands to reason that ideas which are opposed by many in the stream will find it difficult to survive for long periods of time. The policy stream represents a transnational (EU) sub-systemic level of analysis closely paralleling those in domestic policy-making. Members of national policy networks may also be involved in EU policy networks (Kriesi, Adam, and Jochum 2006).

How is agreement achieved? There is no one way to do this; agreement may be attained on the basis of participation, efficiency, power, inclusiveness, or justice. For example, the absence of participation in a key hearing or consultation round with the Commission robs an idea from its key advocate at a propitious moment in the process. Many ideas in EU education policy owe their duration of survival to the presence or absence of such powerful specialists (Corbett 2005). Issues such as streamlining and shortening the review process of mergers at the Commission have gained support among business firms on the basis of efficiency (Cini and McGowan 1998). Quite often the predispositions of key participants bias the rate of survival. The fact that many if not most officials in the Competition DG had until recently a background in law ensured that ideas emphasizing legal sensitivities were looked upon more favorably or with less scrutiny than ideas based strictly on economic concepts (Cini 2002). At other times, the Commission or Parliament seeks input from previously less involved groups to oppose certain ideas or legitimize others. For example, the Commission's role in fostering a dialogue between the social partners at the European level legitimized the potential influence of organized labor in the EU despite direct opposition by member states, including the United Kingdom, and national actors, such as the Confederation of British Industries (Cram 1997, 40-56). The main point is there are many routes to the top without any one of them being more frequently used or more important than the others. 
Technical feasibility refers to ease of implementation. Does the idea appear to be implementable with minimal problems? If so, the ideas chances of survival in the policy stream greatly improve. The notion of positive and negative integration (Scharpf 1996) captures to an extent the essence of the concept. Negative integration refers to the dismantling of national obstacles to the creation of the single market. Positive integration refers to the creation of new rules or institutions to create the single market. Negative integration is much easier to implement because dismantling tariffs, for example, can become effective with the stroke of a pen. Staffing and empowering a European agency responsible for managing Europe-wide pensions is far more difficult to establish.

A special (but not the only) problem of EU implementation is the issue of cost (Zahariadis forthcoming). In times of budgetary constraints, ideas that appear to be particularly costly if implemented stand a lesser chance of receiving serious consideration. For example, labor regulations that demand the creation and staffing of new agencies at the EU and/or national levels are less likely to survive because most member states will bulk at the cost of implementing them.

The other element affecting an idea's availability in the policy stream is the structural integration of policy networks. The term denotes a group of individuals who share a basis of knowledge and interest about certain policies, e.g., labor policy. But emphasis is on relations among actors, not on the actors themselves (Adam and Kriesi 2007). The term should be distinguished from the stability of linkages between actors found in policy communities, the shared beliefs found in tightly-knit advocacy coalitions (Sabatier and Weible 2007), and the ad hoc boundaries of issue networks (Richardson 2001). Ideas are debated in policy networks, but their emergence does not always follow what Kingdon (1995) has termed as a long period of softening up. The concept refers to the process by which solutions establish their viability in the policy stream. Its tempotemporal movement from glacial to rapid-and mode - substantive content from marginal change to completely new-differ dramatically across issues and networks. Combining the two dimensions yields a matrix with four possibilities (Durant and Diehl 1989). Zahariadis and Allen (1995) elaborate on this process, linking it to network integration (Figure 2).

Figure 2 about here

Based on structural characteristics, networks may be classified as more or less integrated. More integrated networks are smaller in size, have a consensual mode, higher administrative capacity, and more restricted access. Conversely, less integrated networks are larger in size, have a competitive mode, lower administrative capacity, and less restricted access. Less integrated networks are more likely to facilitate a quantum to gradualist evolution and more integrated networks are more likely to follow an emergent to convergent pattern.

Less integration makes contact among participants more chaotic and adversarial, leading to innovative ideas swiftly entering the stream. The tempo, however, is likely to 
slow down over time as specialists pick and choose certain elements to recombine them into "new" solutions. Higher numbers of participants increase the likelihood that more new ideas will enter the stream. Exchange in networks based on competition is characterized by infrequent and chaotic contacts between participants and the logic of adversarialism. Under such conditions, ideas are likely to enter the policy stream quite abruptly without regard for continuity with pre-existing policies. Conversely, networks in which participants are consensus-seekers have more frequent and more formalized overt or covert contacts where bargaining prevails. Because such logic of exchange stresses common interests and a search for unanimity and in order to make such meetings more than just trial-balloon arenas, ideas tend to be worked out internally within participants, such as unions, before they are aired in public. Once some of the details are ironed out, the formal presentation in public is likely to increase the idea's appeal. Moreover, intense bargaining with other participants means that amendments to accommodate others are likely. In these situations, we would expect slow entry into the stream and a fairly long softening process which will occasionally be punctuated by rapid propulsion into salience. The evolutionary pattern would flow from emergent to convergent.

While the selection criteria for idea survival mirror those of domestic policymaking, the structure of EU policy networks does not. The point reinforces the argument made earlier that institutions may be different but the activities of participants remain largely the same. Ideas survive in the policy stream following basically the same pattern as they do in domestic policy-making: they are debated, stretched, eliminated, and advocated on the basis of efficiency, equity, or power. Moreover, their likely ease of implementation increases their chances of viability. However, these processes take place in different institutional environments. The biggest differences in structure include the number of participants and degree of access to the network. EU policy networks tend to contain much larger numbers of participants. Part of the reason stems from the fact that there are more stakeholders involved in the EU than the national level (Richardson 2001). For one, there are now at least twenty-seven national agencies with scores of interest groups, bureaucracies, and other actors. In light of the importance of EU decisions for national policies, each feels the need to be involved and have a say in the final outcome. ${ }^{3}$ Moreover, while some groups may be represented collectively at the EU level, e.g., business through UNICE, individual firms also feel the need to maintain separate representation to add more weight to their own individual interests. EU networks are also unique in that the Commission plays an important "hub" role. Few such structures typically exist at the national level. One of the most important functions of the Commission is that of information producer and disseminator, driven partly by the need for legitimacy and bargaining advantage (Nugent 2001).

Both differences coupled with the consensus-seeking mode that characterizes some EU politics create interesting policy dynamics. On the one hand, as the number of participants expands, structural integration decreases. On the other hand, a consensusseeking mode, carefully pieced together and nurtured by the Commission, leads to more integration. These two changes pose challenges for the trajectories of ideas in policy networks. While the substantive germination process, i.e., mode, may remain the same as the possibility of new ideas or recombinations remains similar in both EU and national 
levels, the tempo may segment along predictable lines. Areas where the Commission already plays a major role, such as trade or competition policies, may consistently exhibit a shorter period of softening up. While continued consensus-seeking tends to prolong debate and careful delineation of issues, the increasing number of participants implies a swifter trajectory. As participants continue to multiply exponentially, and assuming no erection of institutional barriers to access, the consensus-seeking days of the Commission may be numbered. Increasing complexity produces decentralizing tendencies (Zahariadis 2003b), potentially robbing the Commission of its gatekeeping function. In light of these trends, ideas are likely to follow a trajectory along the quantum-convergent axis in areas where the Commission still maintains influence. In other areas, such as foreign policy, the process of softening up will be longer along the more familiar emergent-gradualist axis. In the latter cases, different actors or coalitions will try to block or ignore new ideas that do not conform to prevailing values. Such patterns of mutual adjustment elongate the softening up process.

\section{Policy windows}

Policy windows are politically opportune moments in time. They open in either the problem or the politics stream, and they are either predictable or unpredictable. Moreover, while they frequently open on their own, they are sometimes opened by specific individuals.

Policy windows are fleeting "opportunit[ies] for advocates of proposals to push their pet solutions, or to push attention to their special problems” (Kingdon 1995, 165). They represent the catalysts, not the reasons, which help circumscribe the context for action. In other words, they provide the stimulus for choice, but they do not determine the outcome. As Pierre and Peters $(2005,74)$ maintain, "decisions cannot be made if all the requisite elements do not come together in time.” But agendas may be altered by the presence of open windows. Policy windows signify the temporal component of the policy-making process by infusing a sense of urgency; they signal to policy entrepreneurs the temporal limits of the coupling process.

The literature is replete with the importance of such "opportunity structures," but there is no attempt to link them to other variables in the policy process. For example, Héritier (2003) highlights the importance of opportunities and the role they play in enhancing or inhibiting policy effectiveness. Similarly, Cram $(1997,40)$ highlights the importance of negotiations over the Single European Act as providing the "window of opportunity which the Commission required to launch a renewed offensive on the social dimension.” Ekengren (2002, 59-60) maintains that in EU policy-making timing is crucial; it anticipates and forestalls actions by other participants. Acting at a politically opportune time, "the national stance is given better conditions to affect the outcome: 'the sooner the idea is known by others, the easier it is to rally support behind it and to build coalitions with like-minded partners.”' The political advantage is to anticipate and forestall, not just to be first. Nevertheless, Ekengren does not fully analyze the implications of his concept to the EU policy-making process. 
Policy windows may open in the problem or politics stream. For example, the leak of nuclear material in Chernobyl opened a problem window while the resignation of the Santer Commission opened a political window. Windows alter the dynamics of agenda-setting when the influx of new policy makers points to important problems that need to be addressed or when the emergence of new problems animates policy makers to do something about them. While problems are scarce and ephemeral, they bias choice by fixing attention on certain issues and by structuring the search for available solutions in predictable ways (Zahariadis 2007). One of the defining characteristics of multiple streams is that the temporal dimension of choice alters the problem-solution sequence. Most studies of policy-making adopt a rational view of the process where problems are first identified and solutions are then developed to address those problems. In contrast, multiple streams contends that windows structure the process, leading frequently to the paradoxical outcome of solutions chasing problems. As Kingdon (1995, 205-6) categorically asserts, "advocacy of solutions often precedes the highlighting of problems to which they are attached." Zahariadis (2003a) more fully specifies the impact of windows on the problem-solution sequence.

Windows opening in the politics stream foster a doctrinal (solution-problem) sequence. There are four reasons why this is likely to be the case (Zahariadis 2003a, 73). First, it is easier to scan for solutions than for problems. While there is potentially an endless list of serious policy problems, there are only a limited number of solutions. The reasons are significant limitations in time and resources needed to develop solutions. Pointing to solutions first, satisfies policy makers politically because it gives them the aura of control over what issues may be raised and how they may be defined. Second, an electoral victory is perceived by the incoming members of Parliament or the Council as approval for enacting (or opposing) promised policies. Third, rapid technological change frequently leads to the discovery of previously unnoticed problems. Fourth, success of an instrument or idea in one policy area legitimizes its adoption in another. Social policy or education policy is replete with the Commission's attempts to take advantage or open policy windows to promote policies whose details had already been worked over (Cram 1997; Corbett 2005).

Windows opening in the problem stream encourage a consequential (problemsolution) sequence. This is the typical picture of public policy. The emergence of a problem, such as the bird flu, pointed attention to glaring deficiencies in health systems across the EU and prompted search for specific solutions and policy coordination. The negative repercussions of climate change led to EU attempts in 1992 to introduce a common $\mathrm{CO}_{2}$ /energy tax that would curb gas emissions (Andersen 2001, 117).

Timing and context have recently been given considerable prominence in studies of policy choice (Zahariadis 2003a; Richardson 2001; Andersen and Elliassen 2001; Ekengren 2002; Pierre and Peters 2005). A pivotal concern is that utility-maximizing models of choice inject a sense of purposive action that is not present in many cases of policy-making (Stone 2002). Policy windows provide a good way to understand the frequent limitations of rationality and to specify the conditions for deviations from linear, rational conceptions of the policy process. 


\section{Policy entrepreneurs}

Policy entrepreneurs are individuals or corporate actors who try to couple or join the streams together. They are more than just advocates of policy ideas; they are power brokers who manipulate problematic preferences and unclear technology and exploit the system's fluid participation rates to push forth their pet solutions. They more than just support or advocate innovative solutions (Mintrom 2000); they also actively oppose rival ideas. From an individual's point of view, they behave opportunistically (Christopoulos 2006), but from a system's point of view, they create meaning for policy makers with problematic preferences. Manipulation encompasses both views clarifying March's $(1997,23)$ argument: “decision making may, in many ways, be better conceived as a meaning than as an action factory.”

Any actor or participant to the policy process may conceivably act as an entrepreneur. It's not a state of being but of doing. How does one become an effective entrepreneur?

The most important property of effectiveness is persistence. Policy entrepreneurs spend time researching, advocating, and waiting for the right moment (Kingdon 1995). Because they need to present their ideas to a political audience at times over which they have little control, they need to spend time softening up the policy stream and mobilizing support when needed. A keen sense of timing is essential. But there is more to it than that. Knowing what happens in other areas is equally important. Developing a good understanding of how their narrow concern fits within developments elsewhere helps entrepreneurs refine their proposals and arguments (Mintrom 2000, 141). In other words, coalitions and networks need to also be built and nurtured outside the policy stream in order to facilitate coupling. While preparing the ground for coupling is a constant part of entrepreneurial life, activating coalitions outside the policy stream takes place during open policy windows.

Effectiveness is also enhanced by two more elements. Access is essential. Entrepreneurs who have access to the centers of power are more likely to be successful than others. Access is a function of two dimensions: position and presence (March and Romelaer 1976). Position is tied to relational attributes (Christopoulos 2006). For example, position within a hierarchy gives some individuals access to policy makers to "make their case." In their institutional capacity Commission officials frequently serve this function well. They not only have the mandate to formulate proposals, but they also serve as gatekeepers of information in EU policy networks (Nugent 2001). But position alone does not ensure effectiveness. Policy entrepreneurs gain access through presence. One has to be present at the right meetings and venues to forcefully make the case. The configuration of informal networks and the nature of the process further amplify the opportunities for presence increasing the chances of success. For example, Commissioners P. Sutherland and M. Marin were able to navigate interminable meetings, while M. Richonnier and H. Jones, high-level officials in the Education DG, successfully built coalitions with Parliament and the Council to help pass the Erasmus proposal in 1987 (Corbett 2005). 
Resources are a key property of effectiveness. Policy entrepreneurs devote or create resources to soften up the policy stream and couple the three streams together at opportune times. Apart from time, entrepreneurs devote money to produce and disseminate information to sway important constituencies. All interest groups and their lobbyists in Brussels engage in this activity to a varying degree of success (Greenwood 2003). At times, entrepreneurs may create organizational capacity at some point in time so that it may serve as the facilitator for more positive feedback in the future. H. Jones, the director of education training and youth in the 1970s and 1980s, was instrumental in moving the directorate to the DG of social affairs. He did so because he considered its activities heavily constrained by the ineffectiveness of the institutional structure of the time and because he believed that social affairs would provide more opportunities to further his activities (Corbett 2005, 108-9).

Choice is facilitated by agents of policy change. Entrepreneurs not only fix attention to particular problems and solutions, but they also direct the search process, actively support their own or oppose rival solutions, and skillfully use time, access, and resources to couple the streams together. As (Pierre and Peters 2005, 59-60) categorically assert, "individual entrepreneurs become the crucial means of producing action. The centrality of individuals is not only a result of personal power and political skills, it may also be a function of the uncertainty of the situation and the desire of participants to be able to associate proposals for resolving the issue with individuals who advocate them." Although no one person controls the process, entrepreneurs have the power to manipulate ideas and institutions and bias choice toward certain outcomes. The advantage entrepreneurs have in the process does not stem from advantages conferred upon by institutional design. In fact, the EU is notorious for its fluid and adolescent institutional environment. Formal rules regulate access and protect, to an extent, the rights of minorities in the decision-making process (Pierre and Peters 2005, 61). In the absence of institutional constraints or a central authority, entrepreneurs are free to use their skills effectively to pursue their own objectives. In the presence of loose couplings with few rules and generous ambiguity, entrepreneurs can short-circuit the process. Paradoxically, political power in the form of entrepreneurial dominance is likely to play a bigger role in the more open and accessible EU policy process relative to more institutionalized and closed domestic policy processes.

\section{The Dynamics of Coupling}

Each part of the process has been discussed in isolation from the others. It is now time to analyze the process by which all parts are coupled together into a single "package." The process is labeled coupling, and it consists of joining together the streams during open policy windows. I first discuss the various strategies of manipulation that policy entrepreneurs use to couple the streams together, and then I probe the implications of different modes of EU policy-making on the dynamics of coupling.

Policy entrepreneurs use various strategies of manipulation to couple the streams

together thereby manipulating the actual selection process. They don't decide on policies, 
policy makers do. But they bias choice toward some options and away from others. Entrepreneurs must recognize and exploit opportunities. It's not enough for policy windows to open in the politics or problem streams. Entrepreneurs must perceive them as opportunities. Skillful entrepreneurs are not only innovative and socially perceptive; they must maintain substantial contacts with external networks so that they may build coalitions at the time of coupling. Perceptiveness necessitates knowledge and skills. One has to first become knowledgeable of the technical dimensions of the issue. Then one must be skilled at adapting this knowledge to different environments. As Mintrom (2000, 271) puts it, "with social perceptiveness, policy entrepreneurs can develop understandings of the ways that other people look upon social conditions and, from there, begin to establish how others are likely to react to given proposals for policy change." The point is that the coupling process privileges those with technical expertise and knowledge of the whole process. Policy entrepreneurs must be able to recognize an opportunity by connecting their knowledge of the issue with the proclivities of policy makers at opportune times.

While most analysts of multiple streams specify windows as opening independently of entrepreneurs, some analysts (Cram 1997; Corbett 2005) claim that entrepreneurs must also be adept at forcing some windows to open or open windows for others to exploit. Again most examples are drawn from officials within the Commission although others in Parliament or the Council can play the same role. In light of rapid technological advances in the 1970s and 1980s, the Commission encouraged liberalization and deregulation at the national level. In this way, Commissioner E. Davignon (Industry) and Director-General M. Carpentier (Telecommunications, Information Industry, and Innovation), under the capable leadership of J. Delors, were able to create a policy vacuum in EU information and communication technology policy. The vacuum opened a policy window, which the Commission later was only happy to exploit (Cram 1997, 88). O. Guichard, France's education minister in 1969-1972, proposed to The Hague Summit in 1969 the creation of an EC Council of ministers of education to foster political cooperation. His motive was to address some of the national problems caused by the student revolt of 1969 but also to open up the window for Parliament in collaboration with the Commission to propose their own institutional innovations in the field of higher education (Corbett 2005, 55-6).

Coupling the three streams is more likely when entrepreneurs frame issues appropriately. Coupling involves more than persuading policy makers to adopt a particular proposal. It involves activating particular dimensions of the problem to fit the solution in language that appeals to different policy makers (Mintrom 2000, 137). Information is not value-neutral. Entrepreneurs build frames that convey particular meaning to different audiences, building coalitions and containing conflict (Schön and Rhein 1994). Such frames must speak not only to ideological proclivities of ministers in the Council but their national perspectives as well.

Analysts have identified two theories that illuminate the use of policy frames: prospect theory and affect priming. Cognitive changes in how situations are described or framed have predictable effects on what choices policy makers make. A fundamental 
insight is that people tend to be loss averse, that is, they hate to lose more than they like to win (Tversky and Kahneman 1981). Using this insight and applying it to national policy-making, Zahariadis (2003a, 88) argues that if solutions espoused by entrepreneurs are large deviations from the status quo, successful coupling is more likely when problems are represented as losses; if options represent smaller deviations or a preservation of the status quo, coupling success is more likely when problems are framed as gains. Because losses are valued more than gains, risky options (or large deviations from the status quo), are more likely to be adopted if they are linked to problems, which are represented as losses. They require a greater tolerance for risk-taking behavior. Affect priming claims emotion influences behavior via mood congruence. Happy individuals look for cues and interpret their world in ways that highly agree with their mood. Emotion fixes attention and biases search for alternatives while cognition shapes frame interpretation and bias the selection process (Zahariadis 2005).

Effective entrepreneurs often use salami tactics to couple the streams. Policymaking involves a series of decisions which are interconnected. A salami tactic is the strategic manipulation of sequential decision-making (Maoz 1990). Entrepreneurs are assumed to have a grand design of the desired outcome. However, because they are reasonably certain their desired solution will not be adopted because it's too risky, they cut the process into distinct stages, which are presented sequentially to policy makers. Doing so promotes agreement in steps. By the time policy makers become aware they are being manipulated, they have invested too much to depart from the course of action. They end up accepting an outcome in steps they would have rejected as a whole. There are three reasons for this paradoxical outcome: path dependence, sunk costs, and the endowment effect. Prior decisions preclude certain options and favor others (Pierson 1996). Resources already invested in the process or an outcome bias toward continuing it. The endowment effect refers to overvaluation of current possessions. If the proposed policy deviates substantially from the status quo and is therefore less likely to be adopted by risk-averse policy makers, entrepreneurs will cut the process into discrete and seemingly unrelated stages. Manipulating policy images as positive or negative ensures agreement in several steps. Once the desired outcome becomes obvious to those being manipulated, path dependency and sunk costs bias decisions toward continuing the same policy even though the final outcome would not have been accepted on its merits had it been presented and voted upon at the outset.

Does variation in policy-making modes affect the dynamics of coupling? Wallace (2005), for example, identifies five different ways that policy is made: the Community, regulatory, distributional, policy coordination, and intensive transgovernmentalist modes. Differences may be aptly summarized along a continuum containing two dimensions: issue characteristics and institutional involvement and structure. For example, transgovernmentalism involves many different member states but few other EU institutions. On the other hand, the Community method involves most EU institutions.

Looking at the question from an issue perspective, the answer is probably no. Different issue characteristics don't affect the nature of coupling (Zahariadis 2003a). While distributional properties may make agreement among actors substantively more 
difficult, coupling still involves a confluence of problems, solutions, and politics. Policy entrepreneurs still need to use the same strategies to sway policy makers in their favor during open policy windows. Where change may be observed is in duration. Distributional issues take a longer time to soften up in the policy stream due to a wide range of opinions regarding equity and social justice and the larger number of actors involved.

Looking at it from an institutional perspective, the answer is yes. Once ideas become entrenched, they become institutionalized. This fact further insulates them from negative feedback, leading to more change along the lines indicated through positive feedback. This possibility is most likely in autonomous hierarchies. The reason is twofold. First, by definition it is easier in hierarchies to transmit information and enforce policy change from top to bottom than the reverse. Assuming encasement of ideas in institutions, it is logical to expect more choice to favor and reinforce the prevailing orthodoxy (True et al 2007). Second, autonomy preserves the capability of institutions to contain or resist cascading changes dictated by the broader system, filtering away those deemed unfavorable to local elites.

In light of the mostly informal and opaque EU policy process, what Benz (2003, 100) labels “de-institutionalization of decision-making," coupling becomes generally far more difficult to accomplish at the EU level than the national level. The EU has many access points (Peters 1994). Institutional channels of communication vary across issues, while the impact of particular institutions is informal, fluid, and uncertain. For example, much formal policy-making in national settings takes place within well established institutions of government or the parliament. In contrast, the Parliament exercises considerable agenda-setting and decision-making influence sometimes in some areas but not in others. Similarly, the Commission has significant agenda-setting and intermediary power in many areas but not in others. What emerges is a picture of an institutionally autonomous but not hierarchical environment.

The end result is likely to lead to predictable patterns of policies. On the one hand, in coupling situations of autonomy and hierarchy, i.e., where participation is restricted but autonomy is encouraged-e.g., consultation procedure, EU regulations, and the like-choice will be biased in favor of positive rather than negative feedback. Policy entrepreneurs will encounter fewer problems implementing solutions favoring positive amplification of deviations from the status quo for the reasons mentioned above. On the other hand, in coupling situations of autonomy but no hierarchy, i.e., those that involve many participants and more-or-less equal institutions, choice is likely to favor the status quo or small deviations from it. The argument goes beyond familiar notions of incrementalism in public policy (Hayes 2006). From a system’s point of view, institutional autonomy fosters small deviations whether positive or negative while the absence of a hierarchy prevents significant doses of positive feedback.

The process of coupling may also be elongated depending on the policy-making mode. As the number and iterations of actor interaction increases, there is more political conflict and less agreement. Because policy windows are ephemeral, the longer it takes 
for coupling to occur, the greater are the chances that the opposition can muster support to oppose change. Consequently, solutions proposing policy change under co-decision are less likely to pass than under consultation. The paradoxical implication is that although the co-decision procedure was adopted to enhance the power of Parliament, the Council can maintain its superior power by having adopted rules biased against changing the status quo.

Entrepreneurs are well advised to engage in strategic venue-shopping. Successful coupling involves the exploitation of institutional biases. This is true not only in agendasetting (Princen 2007), but fundamentally in decision-making. Given the wide range of decision-making rules in the EU, the number of actors and the consequent degree of needed agreement vary dramatically (Moser, Schneider, and Kirchgässner 2000). For example, the number of actors (and iterations) involved in the co-decision procedure differs dramatically from that of consultation. Despite some Treaty guidance as to what issue needs to be discussed under what procedure, there is considerable ambiguity and hence room for manipulation.

Entrepreneurs may use EU-level institutions where they anticipate a more sympathetic hearing. Interest groups regularly engage in this type of behavior (Richardson 2000). Because issues that fall under EU purvey are normally considered to be cross-national, successful entrepreneurs may frame their arguments in ways that highlight cross-national dimensions. In an increasingly globalized world and a constitutionally anchored single European market, “bringing out” the cross-national dimensions of issues, previously thought of as purely domestic, should not be very difficult as U.S. federal and civil rights leaders discovered in the 1950s and 1960s. ${ }^{4}$ The process entails not simply pushing the item high on an EU institution's agenda, but also activating some dimensions over others. The manipulation of frames does not just serve as a convenient device to forge agreement, but also as an institutional device to manipulate the number of decision makers. In this case, coupling success crucially depends on whether the solution deviates from the status quo (and how much) and what decision rules are followed.

\section{Conclusion}

In the context of loose couplings, I have argued that multiple streams can illuminate the EU policy process and explain outcomes. Peters $(1994,20)$ argues that multiple streams accurately describes the EU's agenda-setting process, but "the questions of policy formulation may be resolved in the manner assumed by more conventional models.” I have taken his argument one step further, applying the lens to the entire process of EU policy formation.

Why do EU policy makers adopt some policies but not others? Persistent policy entrepreneurs are in search of important problems to which they may attach their pet solutions. During open policy windows they attempt to "sell” their problem-solution package to receptive EU decision makers. The chances that a particular option will be adopted increase when all three streams are coupled, depending on the type of open 
window, and the entrepreneurial skills, resources, access, and strategies that focus attention and bias choice.

This picture of policy-making differs radically from other approaches. It uncovers rather than assumes rationality, and it meaningfully synthesizes several incomplete models in a coherent whole. By assuming independence of streams and by specifying the conditions under which the evocation of problems may follow rather than precede that of solutions, multiple streams reveals the limits of rationality. The point is not that policies cannot or are not made in ways assumed by rational models. Rather policies frequently do not follow the linear problem-solution sequence. The key is to specify when that may be the case. Moreover, policy is not always made on the basis of interests and efficiency, as typically assumed by transaction-cost analysts. From the system's point of view, the most important act of policy entrepreneurs is to provide meaning and identity to policy makers with problematic preferences.

The approach also provides a framework to pull together various models in a theoretically meaningful way. It utilizes some elements of policy network theorizing and insight generated by institutional venue-shopping. Each model is an incomplete guide to policy choice by itself (Richardson 2000; Princen 2007). But combined with the logic of manipulation and timing embedded in multiple streams, they provide a more complete explanation of the EU policy process.

Multiple streams stresses the importance of individuals and ideas in policy formation. Policy entrepreneurs broker deals, helping to couple solutions and problems to a receptive political audience. They are clearly an important piece of the puzzle. Ideas are also important, existing independently of specific actors. Commissioners come and go, participants move in and out of the process, but ideas in the policy stream still bubble to the top. Ideas are constantly accepted, rejected, or amended by various participants in the policy stream, in the latter's quest to forge coalitions and enhance the likelihood that their solution will eventually be adopted. Apart from aiming to solve a particular problem, this process also adds political meaning to policy choice by making it easier for policy makers to distinguish between potential friends and foes. Ideas cannot be differentiated from the interests that promote them although they may be differentiated from any one individual who advocates them.

This perspective complements traditional debates which link ideas to institutions (e.g., Garrett and Weingast 1993). Those arguments connect ideas, which are conceptualized more in the sense of paradigms than solutions, to a process of institutionalization. In contrast, multiple streams promotes linkages to the policy process. True, institutions play an important role, but the crucial element missing from traditional debates is the role of actors. Institutions make things possible, but people make things happen. Ideas are loosely coupled to individuals in the sense that they exist independently of any one actor although knowledgeable specialists and skilled entrepreneurs are still needed to push ideas forward. The point is that the study of the EU policy process needs to specify the trajectory of ideas in the narrow policy stream and then explore their 
dynamic transmission and manipulation by entrepreneurs through coupling or spillover to the broader policy system.

Of course, this is not the whole story. Institutions and politics also play a role. The point is not that institutions are not important or are somehow underspecified in multiple streams (Schlager 2007). Multiple streams can be an especially useful lens in cases of what Benz (2003, 100) and Pierre and Peters (2005) label “deinstitutionalized” politics. While one may quibble with their claim that governance is becoming increasingly deinstitutionalized, there is little disagreement as to the adolescence of EU institutions and their informality of contacts and power. Institutions enable the coupling of streams by some entrepreneurs and discouraging others. They constrain as much as they guide the actions and strategies of entrepreneurs (March and Olsen 1989).

Multiple streams sheds light on two important features of EU policy-making. The first feature points to the vital role of political power in the absence of institutional hierarchies. Although the lens differs from traditional models of political power, it still points to its centrality in disorganized, non-hierarchical, loosely coupled systems. Fearful of delegating too much power to EU institutions, member states have opted for a more open-ended, institutionally less crystallized design. Doing so has unwittingly increased the power of EU actors. Power in this case derives not from institutional design but from the ability to dominate the process. In the presence of time constraints and problematic preferences, a relatively small group of policy entrepreneurs with skills, time, and resources are capable of dominating the process and steering decisions toward their favorite outcomes. Fluid participation ensures discontinuity in discourse across venues while opaque technology confers an advantage to the select few who know the "rules of the game.” The more loosely coupled EU policy becomes because of increases in problems or member states, the more powerful policy entrepreneurs are likely to be.

The second feature points to the importance and limits of knowledge as power. Multiple streams stresses the contingent importance of knowledge in the policy process (Radaelli 1995). It highlights the trajectory of ideas in the policy stream and stresses the strategic manipulation of ideas and institutions in coupling the three streams. Traditional arguments regarding the role of epistemic communities accord significant power to experts in scientific communities who can shape the agenda and forge agreement on proposed solutions (Haas 1992; Zito 1999). Multiple streams reinforces these findings by according special emphasis on the role of policy entrepreneurs. They are experts on the substantive aspects of the issue at hand. Knowledge is indeed power, but power is more than just knowledge. Entrepreneurs are also risk-takers who know or understand the rules of the game. They can dominate the process not simply because they understand the issue and its technical aspects. As shown above, that's necessary but hardly sufficient.

Knowledge is important but knowing what to do with it and being able to relate it to different constituencies in order to build coalitions are key elements of success. This is why Commission officials tend to be the more important policy entrepreneurs in EU politics. Their grasp of details at the EU level, their networks of information production and diffusion, and intimate understanding of the policy process confer upon them 
significant advantages over other individuals. Policy dominance in the form of power goes beyond expertise and technocracy (Radaelli 1999).

No one controls the EU policy process. Policy entrepreneurs bias choice, but they alone do not determine the outcome. Member states and the Parliament still play a crucial role in formulating policies. Institutional characteristics still structure the nature of the debate. Nevertheless, problems occur without anyone's prodding. Policy windows frequently open in the problem or politics stream irrespective of solutions. In this environment, serendipity flourishes; there must still be a confluence of three relatively independent streams at politically opportune moments. Multiple streams drives home the point that serendipity and politics are indispensable parts of the same EU policy process. 
Figure 1

Diagram of the Multiple Streams Framework

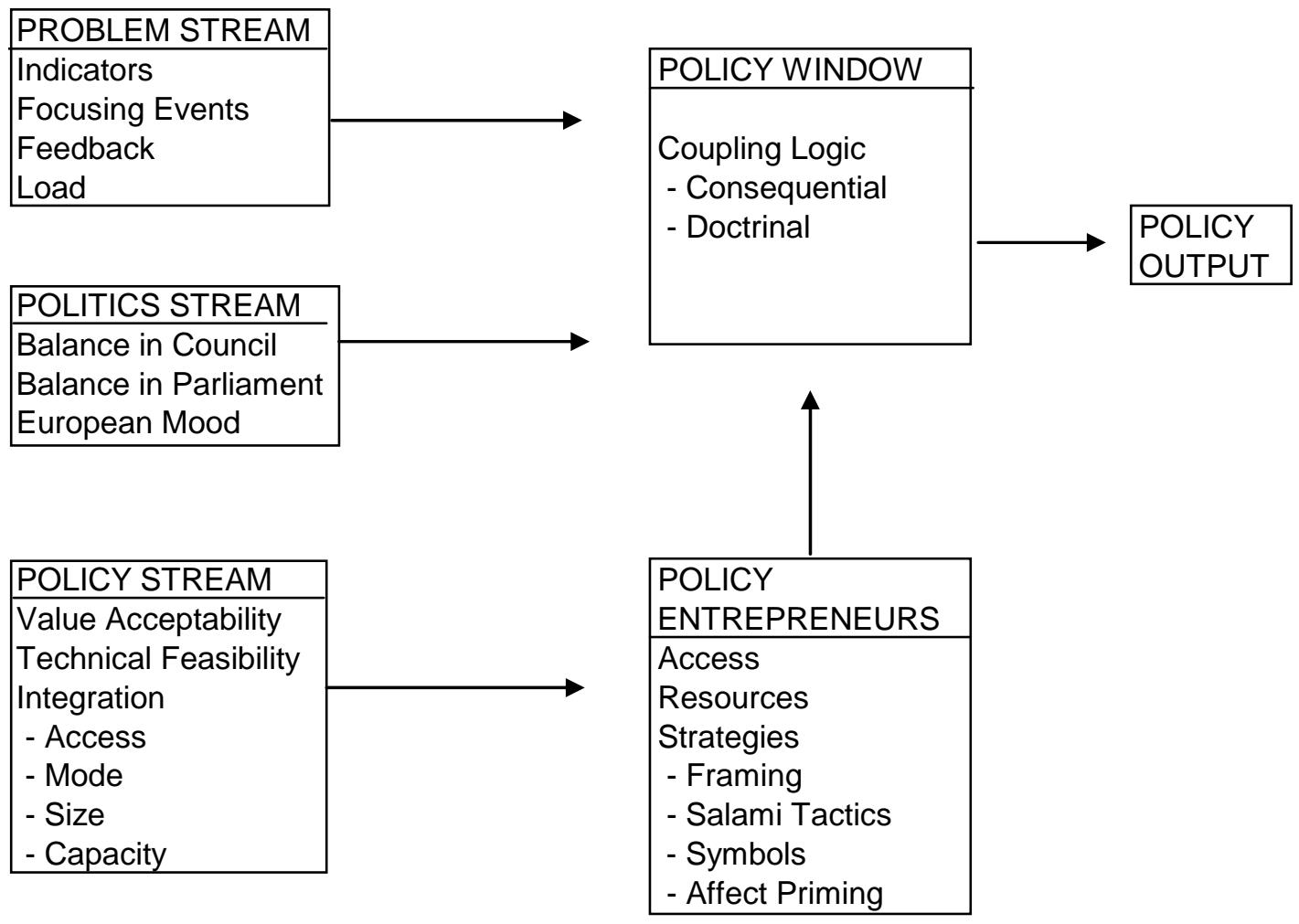

SOURCE: Adapted from Zahariadis (2007) 
Figure 2

Trajectory of Ideas in the Policy Stream

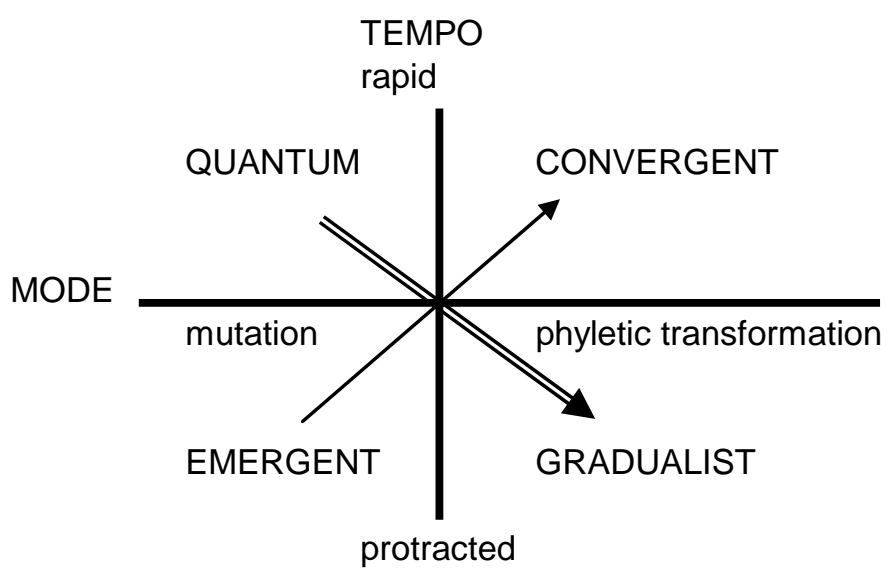

$\longrightarrow$ Trajectory in networks with high integration
$\longrightarrow$ Trajectory in networks with low integration

SOURCE: Zahariadis and Allen (1995) 


\section{References}

Adam, Silke, and Hanspeter Kriesi. 2007. The network approach. In Paul A. Sabatier, ed., Theories of the Policy Process. $2^{\text {nd }}$ ed. Boulder, CO: Westview, 129-54.

Andersen, Svein S. 2001. Energy policy: Interest interaction and supranational authority. In Andersen, Svein S., and Kjell A. Eliassen. Eds. Making Policy in Europe. London: Sage, 86-123.

Andersen, Svein S., and Kjell A. Eliassen. Eds. 2001. Making Policy in Europe. London: Sage.

Benz, Arthur. 2003. Compounded representation in EU multi-level governance. In Beate Kohler Koch, ed., Linking EU and National Governance. Oxford: Oxford University Press, 82-110.

Birkland, Thomas A. 2004. The world changed today: agenda-setting and policy change in the wake of the September 11 terrorist attacks. Review of Policy Research 21: 179-200.

Christopoulos, Dimitris. 2006. Relational attributes of political entrepreneurs: a network perspective. Journal of European Public Policy 13 (5): 757-78.

Cini, Michelle. 2002. The European merger regime: accounting for the distinctiveness of the EU model. Policy Studies Journal 30 (2): 240-51.

Cini, Michelle, and Lee McGowan. 1998. Competition Policy in the European Union. New York, NY: St. Martin's.

Cohen, Michael D., James G. March, and Johan P. Olsen. 1972. A garbage can model of organizational choice. Administrative Science Quarterly 17: 1-25.

Corbett, Anne. 2005. Universities and the Europe of Knowledge. New York: Palgrave Macmillan.

Cram, Laura. 1997. Policy-making in the EU. London and New York: Routledge.

Durant, Robert F., and Paul F. Diehl. 1989. "Agendas, alternatives, and public policy: lessons from the U.S. foreign policy arena,” Journal of Public Policy 9: 179-205.

Ekengren, Magnus. 2002. The Time of European Governance. Manchester and New York: Manchester University Press.

Elder, Charles D., and Cobb, Roger W. 1983. The Political Uses of Symbols. New York: Longman.

Featherstone, Kevin, and Claudio Radaelli. Eds. 2003. The Politics of Europeanization. Oxford: Oxford University Press.

Feldman, Martha S. 1989. Order without Design: Information Production and Policy Making. Stanford: Stanford University Press.

Franklin, Mark. 2001. European elections and the European voter. In Jeremy Richardson (ed.), European Union: Power and Policy-Making. $2^{\text {nd }}$ ed. London and New York: Routledge, 202-16.

Garrett, Geoffrey. 1998. Partisan Politics in the Global Economy. New York: Cambridge University Press.

Garrett, Geoffrey, and Barry R. Weingast. 1993. Ideas, interests, and institutions: constructing the European Community's internal market. In Judith Goldstein and Robert O. Keohane, eds. Ideas and Foreign Policy. Ithaca: Cornell University Press, 173-206.

Graziano, Paolo, and Maarten P. Vink. Eds. 2007. Europeanization: New Research Agendas. New York: Palgrave Macmillan. 
Greenwood, Justin. 2003. Interest Representation in the European Union. New York: Palgrave Macmillan.

Haas, Peter. 1992. Introduction: epistemic communities and international policy coordination. International Organization 46 (1): 1-35.

Hayes, Michael T. 2006. Incrementalism and Public Policy. Lanham, MD: University Press of America.

Heinelt, Hubert, Tanja Kopp-Malek, Jochen Lang, and Bernd Reissert. 2003. Policy making in fragmented systems: how to explain success. In Beate Kohler Koch, ed., Linking EU and National Governance. Oxford: Oxford University Press, 13553.

Hix, Simon. 2005. The Political System of the European Union. $2^{\text {nd }}$ ed. New York and London: Palgrave Macmillan.

Hooghe, Liesbet, and Gary Marks. 2001. Multi-level Governance and European Integration. Lanham, MD: Rowman and Littlefield.

Jones, Bryan D. 1994. Reconceiving Decision-Making in Democratic Politics: Attention, Choice, and Public Policy. Chicago: University of Chicago Press.

Jones, Bryan D., and Frank Baumgartner. 2005. The Politics of Attention. Chicago: University of Chicago Press

Kingdon, John W. 1995. Agendas, Alternatives and Public Policies. $2^{\text {nd }}$ ed. New York: Harper Collins.

Kriesi, Hanspeter, Silke Adam, and Margit Jochum. 2006. Comparative analysis of policy networks in Western Europe. Journal of European Public Policy 13: 34161.

Majone, Giandomenico. 1996. Regulating Europe. New York: Routledge.

Maoz, Zeev. 1990. Framing the national interest: The manipulation of foreign policy decisions in group settings. World Politics 43: 77-110.

March, James G. 1994. A Primer on Decision Making. New York: Free Press.

March, James G. 1997. Understanding how decisions happen in organizations. In Zur Shapira, ed.,Organizational Decision Making, 9-32.Cambridge: Cambridge University Press.

March, James G., and Johan P. Olsen. 1989. Rediscovering Institutions: The Organizational Basis of Politics. New York: Free Press.

March, James G., and Pierre J. Romelaer. 1976. Position and presence in the drift of decision. In Ambiguity and Choice in Organizations, James G. March, Johan P. Olsen, and associates, 251-276. Bergen, Norway: Universitetforlaget.

Mintrom, Michael. 2000. Policy Entrepreneurs and School Choice. Washington, DC: Georgetown University Press.

Moser, Peter, Gerald Schneider, and Gebhard Kirchgässner, eds. (2000). Decision Rules in the European Union. New York: St. Martin's.

Nugent, Neil. 2001. The European Commission. New York: Palgrave.

Olsen, Johan P. 2001. Garbage cans, new institutionalism and the study of politics. American Political Science Review 95: 191-198.

Orton, J. Douglas, and Karl E. Weick. 1990. Loosely coupled systems: a reconceptualization. Academy of Management Review 15 (2): 203-23.

Peters, B. Guy. 1994. Agenda-setting in the European Community. Journal of European Public Policy 1 (1): 9-26. 
Peterson, John. 1995. Decision-making in the European Union: toward a framework for analysis. Journal of European Public Policy 2 (1): 69-93.

Pierre, Jon, and B. Guy Peters. 2005. Governing Complex Societies. New York: Palgrave Macmillan.

Pierson, Paul. 1996. The path to European Integration: a historical institutionalist perspective. Comparative Political Studies 29 (2):123-63.

Pierson, Paul. 2000. Increasing returns, path dependence, and the study of politics. American Political Science Review 94: 251-267.

Pollack, Mark A. 2003. The Engines of European Integration. Oxford and New York: Oxford University Press.

Princen, Sebastiaan. 2007. Agenda-setting in the European Union: a theoretical exploration and agenda for research. Journal of European Public Policy 14 (1): 21-38.

Radaelli, Claudio M. 1999. Technocracy in the European Union. London: Longman.

Radaelli, Claudio M. 1995. The role of knowledge in the policy process. Journal of European Public Policy 2 (2): 159-83.

Richardson, Jeremy. Ed. 2001. European Union: Power and Policymaking. $2^{\text {nd }}$ ed. London and New York: Routledge.

Richardson, Jeremy. 2000. Government, interest groups and policy change. Political Studies 48: 1006-25.

Rochefort, David A., and Roger W. Cobb, eds. 1994. The Politics of Problem Definition: Shaping the Policy Agenda. Lawrence, KS: University Press of Kansas.

Sabatier, Paul A. 2007. The need for better theories. In Paul A. Sabatier, ed., Theories of the Policy Process. $2^{\text {nd }}$ ed. Boulder, CO: Westview, 3-17.

Sabatier, Paul A. 1991. Toward better theories of the policy process. PS: Political Science and Politics 24: 47-156.

Sabatier, Paul A, and Christopher Weible. 2007. The advocacy coalition framework: innovations and clarifications. In Paul A. Sabatier, ed., Theories of the Policy Process. $2^{\text {nd }}$ ed. Boulder, CO: Westview, 189-220.

Scharpf, Fritz W. 1996. Negative and positive integration in the political economy of European welfare states. In G. Marks, F. W. Scharpf, P. C. Schmitter, \& W. Streeck, eds., Governance in the European Union. London: Sage.

Schlager, Edella. 2007. A comparison of frameworks, theories, and models of policy processes. In Paul A. Sabatier, ed., Theories of the Policy Process. $2^{\text {nd }}$ ed. Boulder, CO: Westview, 293-319.

Schön, Donald A. and Martin Rhein. 1994. Frame Reflection: Toward the Resolution of Intractable Policy Controversies. New York: Basic Books.

Sharkansky, Ira. 2002. Politics and Policymaking. Boulder, CO: Westview.

Stone, Deborah. 2002. Policy Paradox. Revised ed. New York: W. W. Norton.

True, James L., Bryan D. Jones, and Frank Baumgartner. 2007. Punctuation-equilibrium theory: explaining stability and change in public policymaking. In Paul A. Sabatier, ed., Theories of the Policy Process. $2^{\text {nd }}$ ed. Boulder, CO: Westview, 155-87.

Tsebelis, George. 1994. The power of the European Parliament as a conditional agendasetter. American Political Science Review 88: 128-42.

Tversky, Amos., and Daniel Kahneman. 1981. The framing of decisions and the 
psychology of choice. Science 211: 453-458.

Wallace, Helen. 2005. An institutional anatomy and five policy modes. In Helen Wallace, William Wallace, and Mark A. Pollack, eds. Policy-making in the European Union. $5^{\text {th }}$ ed. Oxford and New York: Oxford University Press, 49-92.

Wallace, Helen, William Wallace, and Mark A. Pollack. Eds. 2005. Policy-making in the European Union. $5^{\text {th }}$ ed. Oxford and New York: Oxford University Press.

Weick, Karl E. 2001. Making Sense of the Organization. Malden, MA: Blackwell Business.

Wincott, Daniel. 2001. The Court of Justice the European policy process. In Jeremy Richardson (ed.), European Union: Power and Policy-Making. $2^{\text {nd }}$ ed. London and New York: Routledge, 179-97.

Zahariadis, Nikolaos. 2003a. Ambiguity and Choice in Public Policy. Washington, DC: Georgetown University Press.

Zahariadis, Nikolaos. 2003b. Coupling, complexity, and the future of European integration. Review of Policy Research 20 (2): 285-310.

Zahariadis, Nikolaos. 1995. Markets, States, and Public Policy: Privatization in Britain and France. Ann Arbor, MI: University of Michigan Press.

Zahariadis, Nikolaos. 2002. Rethinking European integration in the competition domain: a public policy approach. Policy Studies Journal 30 (2): 229-39.

Zahariadis, Nikolaos. 2007. The multiple streams framework: structure, limitations, prospects. In Paul A. Sabatier, ed., Theories of the Policy Process. $2^{\text {nd }}$ ed. Boulder, CO: Westview, 65-92.

Zahariadis, Nikolaos. forthcoming. Europeanization as program implementation: effective and democratic? Journal of Comparative Policy Analysis.

Zahariadis, Nikolaos, and Christopher S. Allen. 1995. Ideas, networks, and policy streams: privatization in Britain and Germany. Policy Studies Review 14 (1/2):7198.

Zito, Anthony R. 1999. Creating Environmental Policy in the European Union. New York: St. Martin's. 


\section{Notes}

${ }^{1}$ For an examination of the vertical dimension of integration and policy-making, see Zahariadis (2003b).

${ }^{2}$ For an example of the dramatic impact of the national mood and conceptions of nationhood in opposition to certain policy options, see Zahariadis (2005).

${ }^{3}$ The entire literature on Europeanization deals with the impact of Europe on national policies and vice versa. For good recent discussions, see Featherstone and Radaelli (2003) and Graziano and Vink (2007).

${ }^{4}$ Many of the landmark cases of the U.S. Supreme Court were actually based on reinterpreting the limits of federal purview (interstate commerce) rather than on any substantive merits of civil rights per se. 